\title{
Sıçanlarda İntestinal İskemi Reperfüzyon ile Oluşan Akut Akciğer Hasarında Metforminin Koruyucu Etkileri
}

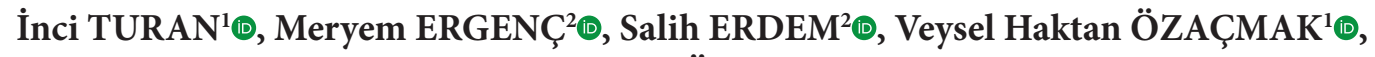 \\ Hale SAYAN ÖZAÇMAK ${ }^{1}$ \\ ${ }^{1}$ Zonguldak Bülent Ecevit Üniversitesi, Tip Fakültesi, Fizyoloji Anabilim Dalı, Zonguldak \\ ${ }^{2}$ Zonguldak Bülent Ecevit Üniversitesi, Sağlık Bilimleri Enstitüsü, Fizyoloji Anabilim Dalı, Zonguldak
}

Bu makaleye yapılacak atıf: Turan İ, Ergenç M, Erdem S, Özaçmak VH, Sayan Özaçmak H. Sıçanlarda İntestinal İskemi Reperfüzyon ile Oluşan Akut Akciğer Hasarında Metforminin Koruyucu Etkileri. Türk Diyab Obez 2018;3: 113-118.

\begin{abstract}
ÖZET
Amaç: İntestinal iskemi/reperfüzyon (İ/R) akciğeri içeren çoklu organ hasarına neden olmaktadır. Pulmoner doku hasarı ve solunum yetmezliği intestinal iskemi sonrası yaygın bir olaydır. Genel olarak serbest oksijen radikalleri (SOR) gibi oksidatif stres mediyatörlerinin İ/R ile oluşan pulmoner hasar gelişiminde rol oynadığına inanılmaktadır. Çalışmamızın amacı, metformin tedavisinin sıçanlarda intestinal İ/R ile indüklenen akut akciğer hasarını azaltıp azaltmayacağını araştırmaktır.

Gereç ve Yöntemler: İntestinal İ/R’nun sıçan modeli süperiör mezenterik arterin 45 dakika bağlanması sonrasında 3 saatlik reperfüzyonu ile oluşturuldu. Metformin intestinal iskemiden beş gün önce oral olarak uygulandı (50,100 veya 200mg/kg dozunda). Wistar Albino cinsi 40 adet sıçan sham konrol, I/R kontrol ve metfornin uygulanan gruplar olarak beş gruba ayrıldı. Oksidatif stresi değerlendirmek amacıyla malondialdehid (MDA) ve indirgenmiş glutatyon(GSH) seviyeleri tespit edildi. Hasarı gözleyebilmek için doku kesitleri hematoksilen eozin ile boyand.

Bulgular: Çeşitli dozlarda metformin ön tedavisi yapılan gruplarda tedavi edilmeyen I/R grubu ile karşılaştırıldığında lipid peroksidasyon seviyesinin önemli ölçüde düştüğü tespit edilmiştir. $200 \mathrm{mg} / \mathrm{kg}$ dozunda metformin ön tedavisi yapılan grupta histopatolojik akciğer hasar skorları diğer gruplarla karşılaştırıldığında anlamlı derecede azalmıştır. Bunlara ek olarak metformin ön tedavisi intestinal İ/R sonrasında akciğer dokusunda GSH seviyelerini normalize etmiştir.

Sonuç: Bu çalışmanın sonuçları, metformin ön tedavisinin intestinal İ/R ile oluşan akut akciğer hasarını azaltmanın etkili bir yolu olabileceğini göstermektedir.
\end{abstract}

Anahtar Sözcükler: Metformin, intestinal iskemi, akut akciğer hasarı, oksidatif stres

\section{Protective Effects of Metformin Against Acute Lung Injury Induced by Intestinal Ischemia and Reperfuson in Rats}

\begin{abstract}
Aim: Intestinal ischemia/reperfusion (I/R) produces multiple organ injury including lung. Pulmonary tissue damage and respiratory failure are prevalent events after intestinal ischemia. It is generally known that oxidative stress mediators such as reactive oxygen species (ROS) is believed to have a role in the development of such I/R-induced pulmonary injury. Under the light of these data, the aim of the present study was to investigate whether metformin treatment would alleviate the acute lung injury induced by intestinal I/R in rats, histolopathologically and biochemically.

Material and Methods: A rat model of intestinal I/R was induced by clamping the superior mesenteric artery for 45 min followed by reperfusion for three hours. Metformin was administrated orally five days before intestinal ischemia (50,100 or $200 \mathrm{mg} / \mathrm{kg})$. Forty
\end{abstract}

ORCID: İnci Turan / 0000-0003-2211-3914, Meryem Ergenç / 0000-0002-0628-4791, Salih Erdem / 0000-0003-3277-0539, Veysel Haktan Özaçmak / 0000-0003-2651-8353 Hale Sayan Özaçmak / 0000-0002-3564-0468 
Wistar Albino rats were randomly assigned to five groups: sham control; I/R control and metformin treated groups. The levels of malondialdehyde (MDA) and reduced glutathione (GSH) were measured in order to evaluate the oxidative stress. Tissue sections were stained with hematoxylin and eosin to visualize the damage.

Results: Pretreatment with various doses of metformin significantly reduced lipid peroxidation levels in lung tissue compared with untreated I/R group. Histopathologic lung injury scores in the group pretreated with $200 \mathrm{mg}$ kg metformin decreased significantly when compared with the other groups. Additionally, metformin pretreatment normalized GSH levels after intestinal I/R in lung.

Conclusion: The results of the present study represent that pretreatment with metformin may be a effective the way of alleviating the acute lung damage induced by intestinal I/R.

Key Words: Metformin, intestinal ischemia, acute lung injury, oxidative stress

\section{GIIRIŞ}

İntestinal iskemi-reperfüzyon (İ/R) hasarı genellikle travmatik şok, kardiyak bypass, karaciğer transplantasyonu ve intestinal transplantasyon gibi çeșitli cerrahi işlemler esnasında meydana gelebilen bir durumdur. Klinik çalışmalar intestinal İ/R sonrasında mortalitenin \%32-77 oranında gerçekleşebildiğini göstermektedir (1). İntestinal dokunun İ/R'u sadece ince bağırsaklarda hasara neden olmaz aynı zamanda uzak organlarda da hasara neden olmaktadır. Bu uzak organ hasarlarının içinde akut akciğer hasarı veya respiratuar distres sendromu yer almaktadır ve bu durum kritik hastalarda mortaliteyi artırmaktadır (2-4). İntestinal dokunun I/R hasarı bağırsak bariyerinin yıkımına neden olmaktadır. Bunun sonucunda serbest oksijen radikalleri (SOR) ve endotoksinlerin sistemik dolaşıma geçmeleri sistemik inflamatuar yanıta ve çoklu organ yetmezliğine neden olmaktadır (5). İntestinal İ/R sonrasında çeşitli risk faktörlerinin akut akciğer hasarının oluşumunun patogenezinde rol oynadığı belirlenmiştir ve bunlar içinde oksidatif stresin temel bir faktör olduğu ortaya konmuştur $(1,4)$. Oksidatif stresin yanısıra nitrik oksit, nötrofillerin birikimi, sitokin ve diğer inflamatuar mediyatörlerin salınımı ve apoptotik hücre ölümü akut akciğer hasarının oluşumunda rol oynamaktadır $(6,7)$. Oksidatif stres oluşumunda etkili olan SOR aynı zamanda çeşitli proinflamatuar sitokinlerin yapımını uyararak akciğer dokusunda epitelyal ve endotelyal hasara neden olmaktadır $(8,9)$.

Metformin biguanid antidiabetik ajanlar ailesinin bir üyesidir ve tip 2 diabetes mellitüsde insülin direncini tedavi etmek amacıyla yaygın olarak kullanılmaktadır. Son yıllarda yapılan pek çok çalışmada metforminin sadece antihiperglisemik etkili olmadığı, kardiyovasküler ve serebrovasküler koruyucu etkiler gösterdiği tespit edilmiștir (10-12). Örneğin serebral iskeminin deneysel modellerinde kan beyin bariyeri yıkımını azalttığı, nörogenezi ve angiogenezi artırdığı (13) ve apoptotik hücre ölümünü engellediği $(14,15)$ gösterilmiştir. Bu etkilerinin ortaya çımasında etkili mekanizmalardan biri serebral iskemi ile oluşan oksidatif stresi azaltmasıdır (16).
Solunum yetmezliği intestinal $\dot{\mathrm{I}} / \mathrm{R}$ sonrasında morbidite ve mortalitenin en sık nedenini oluşturmaktadır. Bu nedenle intestinal $\dot{\mathrm{I}} / \mathrm{R}$ ile ortaya çıkan akut akciğer hasarının moleküler mekanizmalarının anlaşılarak yeni ve etkili tedavi stratejilerinin geliştirilmesi gerekli görülmektedir. Literatürde metforminin çeşitli dokulardaki I/R hasarına karşı koruyucu etkinliğinin gösterildiği çalışmalar bulunmasına karşın intestinal İ/R sonrası ortaya çıkan akut akciğer hasarına etkileri ile ilgili bir çalışma bulunmamaktadır. Bu çalışmada metforminin intesinal İ/R ile oluşan akut akciğer hasarı üzerine olan etkileri biyokimyasal ve histopatolojik olarak incelenmesi amaçlanmıştır.

\section{GEREÇ ve YÖNTEMLER}

Çalışma dişi Wistar Albino cinsi sıçanlar (250-330 g) kullanılarak gerçekleştirilmiştir. Çalışmanın yapılabilmesi için Zonguldak Bülent Ecevit Üniversitesi Deney Hayvanları Etik Kurulundan onayı alınmıştır. Sıçanlar 12 saat ışık 12 saat karanlık döngüsünde ve standart sıçan yemi ile beslenerek Zonguldak Bülent Ecevit Üniversitesi Deney Hayvanları Ünitesinde barındırılmıştır. Çalışmada her grupta 8 sıçan bulunmak üzere toplam 5 grup bulunmaktadır:

Grup I: Sham kontrol grubudur ve deneklerde iskemi oluşturulmadan sadece batın bölgesi açılarak, I/R uygulanan hayvanlardaki tüm işlemler uygulanmıştır.

Grup II: I/R grubu, $45 \mathrm{dk}$ 'llk iskemi ve sonrasinda 3 saat reperfüzyon uygulanan gruptur.

Grup III: İ/R+50mg/kg metformin uygulanan grup. $\mathrm{Bu}$ gruptaki hayvanlar iskemiden 5 gün önce $50 \mathrm{mg} / \mathrm{kg}$ dozunda metformin ile tedavi edilmiştir. Beş günlük metformin uygulaması sonrasında $45 \mathrm{dk}$ 'lı iskemi ve sonrasında 3 saat reperfüzyon uygulanmıştır.

Grup IV: $\dot{\mathrm{I}} / \mathrm{R}+100 \mathrm{mg} / \mathrm{kg}$ metformin uygulanan gruptur. İskemiden 5 gün önce $100 \mathrm{mg} / \mathrm{kg}$ dozunda metformin tedavisi sonrasinda $45 \mathrm{dk}$ intestinal iskemi ve 3 saat reperfüzyon uygulanmıştır.

Grup V: $\dot{\mathrm{I}} / \mathrm{R}+200 \mathrm{mg} / \mathrm{kg}$ metformin uygulanan gruptur. $\mathrm{Bu}$ gruptaki deneklere $200 \mathrm{mg} / \mathrm{kg}$ metformin tedavisi sonrasında intestinal I/R uygulanmıştır. 


\section{İntestinal İskemi Oluşturma Yöntemi}

Deney hayvanları sodyum tiopental $(60 \mathrm{mg} / \mathrm{kg}$, ip) ile anestezi edildikten sonra batın bölgesi açılarak süperiör mezenterik arter izolasyonu gerçekleştirilmiştir. İntestinal iskemi superiör mezenterik arterin $45 \mathrm{dk}$ süre ile $3 / 0$ cerrahi iplik ile bağlanması ile oluşturulmuştur. Mezenterik dolaşımdaki arteryel pulsasyonların kontrolü ve rengin soluklaşması ile intestinal iskemi teyit edilmiştir. $45 \mathrm{dk} l \mathrm{lk}$ iskemi süresinden sonra üç saatlik reperfüzyon periyodu uygulanmıştır. Reperfüzyon, arteryel pulsasyonun geri gelmesi ile kontrol edilmiştir. Üç saatlik reperfüzyon süresinin sonrasında hem histopatolojik çalışma hem de biyokimyasal incelemeler için akciğer dokusu alınmıştır. Histopatolojik inceleme için akciğer dokusundan kesitler alınarak hemotoksilen eozin ile boynamıştır. Oksidatif stres göstergesi olarak lipid peroksidasyonun son ürünü olan malondialdehid (MDA) ve indirgenmiş glutatyon (GSH) biyokimyasal olarak ölçülmüștür.

\section{Histopatolojik Değerlendirme:}

Akciğer lobektomi materyalleri \%10'luk formalin solüsyonunda fikse edildi. Histopatolojik inceleme için parafin bloklardan elde edilen kesitlere hematoksileneosin (H\&E) boyası uygulanarak preparatlar elde edildi. Hazırlanan preparatlar, ışı mikroskobisi ile semikantitatif olarak gruplar bilinmeksizin değerlendirildi.

Elde edilen akciğer kesitleri, Pirat ve ark. (17) tarafından tanımlanan derecelendirmemetodu temelalınarakskorlandı. Akciğer doku hasarı kriterleri: Nötrofil infiltrasyonu, havayolu epitel hücre hasarı, interstisiyel ödem, hyalin membran formasyonu, hemoraji, amfizematöz genişleme. Her bir kriter 0 dan 4'e doğru ilerleyen skala ile skorland (0-normal, 1-minimal değişiklik, 2-hafif değişiklik, 3-orta derecede değişiklik, 4-şiddetli değişiklik).

MDA ve GSH Ölçümüi

Doku MDA seviyesi (nmol/g doku olarak gösterilmiştir) spektrofotometrik olarak Casini ve ark.nın (18) yöntemi temel alınarak ölçülmüştür. Akciğer dokularına ait GSH içeriği ise ( $\mu \mathrm{mol} / \mathrm{g}$ doku olarak gösterilmiştir) modifiye Ellman metodu kullanılarak belirlenmiştir (19).

\section{İstatistiksel Analiz}

İstatistiksel değerlendirme SPSS 19.0 (SPSS Inc., Chicago, IL, USA) programı kullanılarak yapıldı. Tanımlayıcı istatistikler ortanca (minimum-maksimum) olarak ifade edildi. Sayısal değişkenler bakımından grupların karşılaştırılmasında Kruskal-Wallis varyans analizi kullanıldı. Kruskal-Wallis varyans analizinde alt grupların ikişerli karşılaştırılması ise Dunn testi ile yapıldı ve tüm değerlendirmeler için $\mathrm{p}<0.05$ değeri anlamlı kabul edildi.

\section{BULGULAR}

\section{Akciğer Dokusunun Histopatolojik Değerlendirilmesi}

Akciğer dokularının histopatolojik incelemesinde; kontrol grubunda (Şekil 1A) minimal doku hasarı izlenirken, İ/R grubunda (Şekil 1B) belirgin doku hasarı gözlendi. Metformin $200 \mathrm{mg} / \mathrm{kg}$ ön tedavisi yapılan deney grubuna ait kesitlerde (Şekil 1E) İ/Rgrubu ve diğer metformin uygulanan gruplarla karşılaştırıldığında doku hasarında azalma olduğu gözlendi. Metformin $50 \mathrm{mg} / \mathrm{kg}$ ve $100 \mathrm{mg} / \mathrm{kg}$ uygulanan gruplarda İ/R grubu ile karşılaştırıldığında akciğer hasar skorları açısından anlamlı farklılık bulunmamıștır (Şekil 1C,D). Metformin $200 \mathrm{mg} / \mathrm{kg}$ ön tedavisi yapilan deney grubunda minimal amfizematöz değişiklik, hemoraji ve hafif inflamatuar hücre infiltrasyonu olan akciğer dokusu izlendi. Total Akciğer hasarı skoru istatistiksel olarak değerlendirildiğinde metformin $200 \mathrm{mg} / \mathrm{kg}$ uygulanan grup ile İ/R grubu karşılaştırıldığında hasarın istatistiksel olarak anlamlı azaldığ 1 saptand $1(\mathrm{p}<0.05)$ (Tablo 1). Metformin uygulanan gruplar birbirleriyle karşılaştırıldığında total akciğer hasar skoru istatistiksel olarak anlamlı bulunmadı $(\mathrm{p}>0,05)$.

\section{MDA ve GSH Düzeyleri}

İntestinal İ/R sonrası akciğer dokusu MDA düzeylerinin İ/R uygulanan grupta, kontrol ve metformin uygulanan gruplarla karşılaştıııldığında istatistiksel olarak anlamlı bir artı̧ tespit edildi. Metformin ön tedavisi yapılan gruplarda MDA düzeylerinin İ/R grubuna göre istatistiksel olarak anlamlı şekilde azaldığı gözlendi $(\mathrm{p}<0,05)$ (Tablo 1$)$.

GSH düzeyleri İ/R grubunda kontrol ve metformin ön tedavisi yapılan gruplara göre belirgin bir düşüş gözlemlendi

Tablo 1: Metforminin akciğer dokusunda lipit peroksidasyonuna ve total akciğer hasarına etkisi.

\begin{tabular}{cccccc}
\hline & $\begin{array}{c}\text { Kontrol } \\
\mathbf{n = 8}\end{array}$ & $\begin{array}{c}\text { IR } \\
\mathbf{n = 8}\end{array}$ & $\begin{array}{c}\text { Met50 } \\
\mathbf{n = 8}\end{array}$ & $\begin{array}{c}\text { Met100 } \\
\mathbf{n = 8}\end{array}$ & $\begin{array}{c}\text { Met200 } \\
\mathbf{n = 8}\end{array}$ \\
\hline MDA & $38(30-49)$ & $62(48-69)^{*}$ & $49(38-58)^{*}$ & $47(34-62)^{*} \&$ & $46(39-49)^{* *}$ \\
\hline GSH & $5(4-6)$ & $2(1-6)^{*}$ & $3(1-5)$ & $4(3-7)$ & $5(3-7)^{*}$ \\
\hline TAH & $2(1-2)$ & $16(11-18)^{*}$ & $12(10-14)^{*}$ & $10(9-14)^{*}$ & $9(6-10)^{*}$ \\
\hline
\end{tabular}

Değerler ortanca (max-min) olarak alınmıştır. ${ }^{*}$ kontrole göre, ${ }^{\&}$ IR’ye göre $(\mathrm{P}<0.05)$. MDA: Melondialdehid (nmol/g), GSH: İndirgenmiş glutatyon $(\mu \mathrm{mol} / \mathrm{g})$, TAH: Total akciğer hasarı. 
$(p<0,05)$. Metformin ön tedavisi yapılan gruplarda GSH düzeylerinin hem kontrol grubuna ve hem de İ/R grubuna göre anlamlı arttığı saptandı $(\mathrm{p}<0,05)$ (Tablo 1$)$.

\section{TARTIȘMA}

Çalışmamızda intestinal $\mathrm{I} / \mathrm{R}$ ile akciğer hasarına ait histopatolojik hasar skorlarının arttığı tespit edilmiştir. $\mathrm{Bu}$ değişiklikler MDA düzeylerinde artış ile belirlenen oksidatif stres artışı ve azalmış GSH seviyesi ile birliktedir. Metformin ön tedavisi intestinal I/R ile oluşan akciğer hasarına karşı koruyucu etki göstermiştir. Bu koruyucu etkinin MDA seviyesinde azalma ve GSH düzeyindeki artış ile uyumlu olduğu görülmektedir. Akciğer dokusunun histopatolojik incelemesi de metforminin koruyucu etkisini desteklemektedir. Metformin doza bağlı olarak özellikle
$200 \mathrm{mg} / \mathrm{kg}$ dozunda akciğer hasarını azaltmada etkili olduğu tespit edilmiştir.

İntestinal İ/R hasarı kritik hastalarda ve çeșitli cerrahi işlemleri takiben oluşabilen bir durumdur. İntestinal İ/R hasarı sonrasındaki morbidite ve mortalitenin çoğu akut respiratuar distres sendromuna ilerleyen sistemik oksidatif stres ve uzak akciğer hasarından kaynaklanmaktadır $(3,4,9)$. İntestinal İ/R ile oluşan uzak akciğer hasarında oksidatif moleküllerin rolü tanımlanmıștır. Akciğerler SOR’nin aşırı yapımına oldukça duyarlıdırlar. Aşırı serbest radikal üretimi hücrede lipid peroksidasyonu ile zarı ve mitokondri gibi hücresel organellere zarar vererek hücrenin apoptoz ve nekrozuna neden olabilmektedir (20). Bu çalışmada İ/R grubunda akciğer dokusunda gözlemlenen MDA
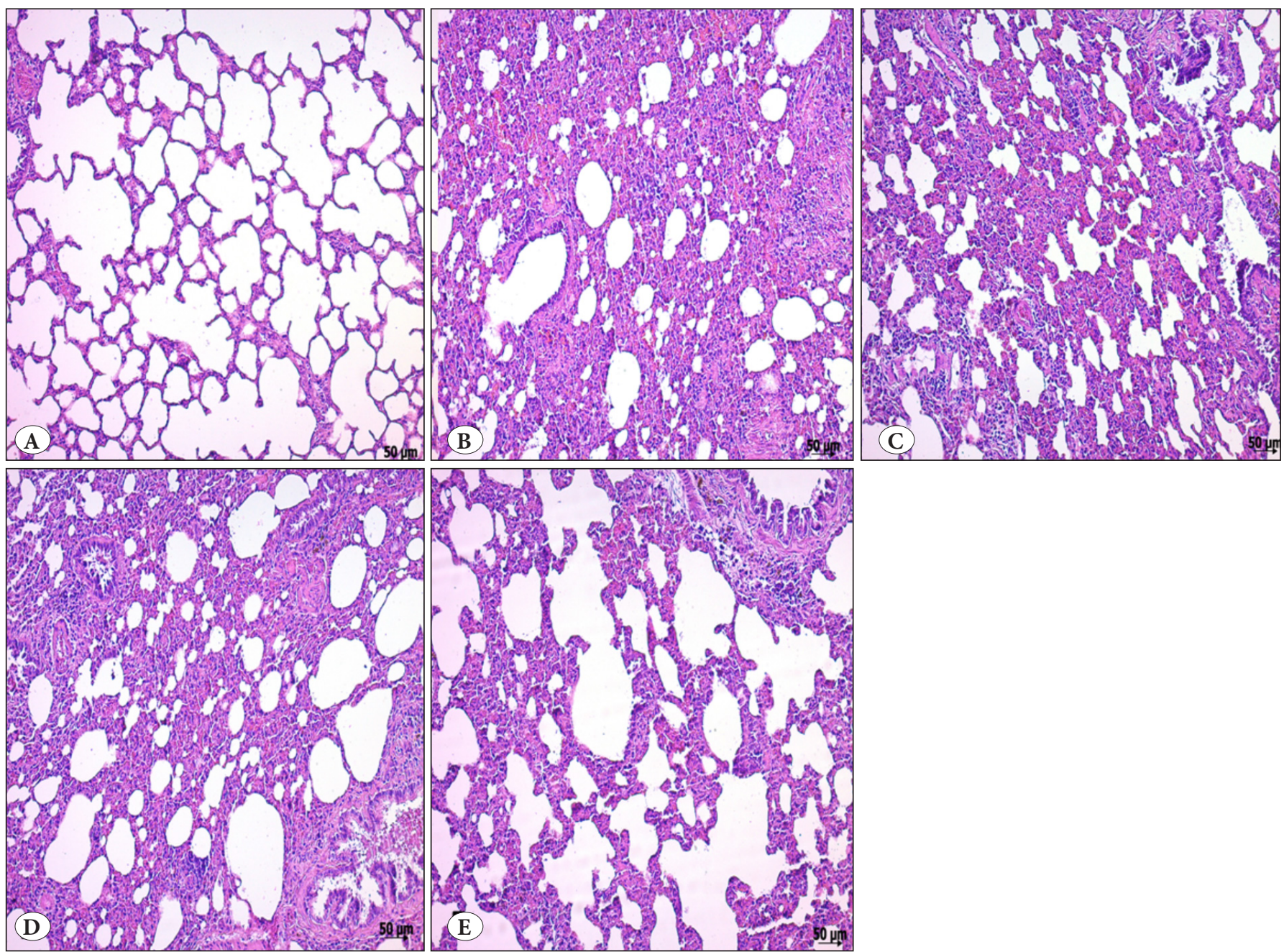

Şekil 1: AC doku resimleri: Akciğer kesitlerine ait histopatolojik görünümler (H\&E, X100). A) Kontrol grubu; minimal konjesyon bulguları içeren düzenli görünümdeki alveoler yapılardan oluşan normal akciğer dokusu. B) İR grubu; bronş duvarında ve alveoler yapılarda belirgin akciğer hasarı olușturan yoğun mikst tipte inflamasyon, ödem ve hemoraji bulguları. C) $\mathrm{I} / \mathrm{R}+50 \mathrm{mg}$ metformin; İ/R grubuna benzer şekilde alveoler yapılarda ve bronş duvarında mikst tipte inflamatuar hücre infiltrasyonu, hemoraji, ve epitelyal hasar izlenen akciğer dokusu. D) İ/R+100 mg metformin; $\dot{I} / R+50 \mathrm{mg}$ metformin grubuna benzer şekilde hasarlı akciğer dokusu. E) $\dot{\mathrm{I}} / \mathrm{R}+200$ mg metformin; kontrol grubuna göre daha fazla, diğer çalışma gruplarına göre daha az hasarlı akciğer dokusu gözlenmekte olup, bu gruptaki akciğer dokularında amfizematöz değişiklik, hemoraji, ve hafif inflamatuar hücre infiltrasyonu izlenmektedir. 
seviyesindeki artış ve GSH düzeylerindeki azalmanın gözlenmesi oksidatif stresin intestinal $\dot{\mathrm{I}} / \mathrm{R}$ sonrası ortaya çıkan akciğer hasarında önemli mekanizmalardan biri olduğunu göstermektedir. Daha önce yayınlanan çalışmalarımızda intestinal $\dot{\mathrm{I}} / \mathrm{R}$ sonrasında akciğer dokusunda lipid peroksidasyonun göstergesi olan MDA düzeylerinin arttığını saptamıştık $(6,21)$. Sistemik olarak salınan oksidatif moleküller pulmoner hücreleri harab ederek alveolokapiller membran bütünlüğünü ve sürfaktan fonksiyonunda kayıplara yol açmaktadır. Akciğer hasarının bir işareti olan alveolar kollaps ve yetersiz gaz değişimi meydana gelmektedir (9).

Bu çalışmada koruyucu bir ajan olarak metformin intestinal İ/R sonrasında ortaya çıan akciğer hasarı üzerine etkisi incelenmiştir. Metformin tip 2 diabet tedavisinde glukoneogenezis inhibisyonu ile hepatik glukoz çıkışını azaltır. Daha az oranda iskelet kası ve yağ dokusuna insülinle uyarılan glukoz girişini artırır. Klinikte metformin kullanan kişilerde inme riskinin ve kardiyovasküler mortalitenin azaldığ 1 bildirilmektedir. Metformin hücresel enerji dengesinin temel düzenleyicisi olan AMP- ile aktive olan protein kinazı(AMPK) aktive eder (16). AMPK'ın aktivasyonun metforminin koruyucu etkinliğinde rol aldığ 1 bildirilmektedir $(4,22)$. Beyin iskemisinde metformin öntedavisinin AMPK aktivasyonu ile mitokondriyal biyogenezi ile ilgili proteinlerin yapımını artırarak ve apoptotik proteinlerin yapımını inhibe ederek koruyucu etkili olduğu bildirilmektedir (15). Özellikle apoptotik hücre ölümünü engellemesi ile ilgili olarak metforminin mitokondriden sitokrom C salınımını inhibe ettiği bildirilmektedir (14).

Metforminin özellikle iskemik beyin dokusunda oksidatif stresi inhibe etmesi nörokoruyucu etkilerinden birisidir. Karimipour ve ark. beyin iskemisi sonrasında MDA seviyelerinin metformin ön tedavisi ile azaldığını göstermişlerdir (10). Karaciğer $\dot{\mathrm{I}} / \mathrm{R}$ hasarında da benzer şekilde oksidatif stres parametreleri metformin tedavisi ile inhibe edilebilmiştir (23). Benzer sonuç Tang ve ark.nın yaptığ 1 çalışmada sepsis modelinde metformin tedavisi ile beyinde oksidatif stresin engellenebildiği gösterilmiştir (24). Çalışmamızın sonuçları da bu çalışmaları destekler şekilde akciğer dokusu MDA düzeyleri metformin ile kontrol seviyelerinde korunabilmiştir ve böylece metforminin önemli bir antioksidan koruma sağlamış olduğu görülmektedir. GSH düzeyleri ise metformin uygulanan tüm gruplarda kontrol ve $\dot{\mathrm{I}} / \mathrm{R}$ grubuna göre anlamlı yükselmiştir. $\mathrm{Bu}$ sonucun metforminin antioksidan etki göstermesinde dokudaki GSH düzeylerini düzenlemesinden de kaynaklanabileceğini söyleyebiliriz.

Histolojik skorlar açısından değerlendirildiğinde $200 \mathrm{mg} /$ $\mathrm{kg}$ dozunda metformin ön tedavisi uygulanan grupta total akciğer hasarının İ/R grubuna anlamlı iyileşme sağlandığ 1 gözlendi. Metformin ön tedavisi ile lipid peroksidayon seviyesindeki azalma ve antioksidant GSH seviyesinde artış nedeniyle pulmoner yapının korunduğu görülmektedir. Ashabi ve ark. yaptıkları çalışmada metforminin $200 \mathrm{mg} /$ $\mathrm{kg}$ dozunun iskemik beyin hasarından korumada en etkili doz olduğunu ortaya koymuşlardır. $100 \mathrm{mg} / \mathrm{kg}$ dozununda metformin uygulaması AMPK aktivasyonuna yeterli olmadığı bildirilmektedir (15). Bu çalışmada da metforminin özellikle $200 \mathrm{mg} / \mathrm{kg}$ dozunda oksidatif strese bağlı akciğer hasarını azaltmada en etkili doz olduğu saptanmıştır.

İntestinal İ/R ile oluşan akciğer hasarını korumak için statinler, antioksidantlar ve surfaktan uygulaması gibi pek çok farmakolojik ajan denenmiştir (7,25-27). Bunlardan bazıları ümit verici sonuçlar verse de hazırlamadaki karmaşıklık ve potansiyel riskler nedeniyle şu ana kadar hiçbiri klinikte uygulanmamaktadır. Sonuç olarak çalışmamızda 200mg/ $\mathrm{kg}$ metformin ön tedavisinin intestinal $\dot{\mathrm{I}} / \mathrm{R}$ sonrasinda akciğer morfolojisini koruduğu, oksidatif stresi azalttığı ve GSH seviyelerini artırdığı gözlendi. Metforminin koruyucu etkisinin arkasında yer alan mekanizmanın oksidatif stresi azaltmasından kaynaklanabildiği görülmektedir. Metforminin I/R hasarı ve uzak doku hasarının önlenmesine ilişkin mekanizmaları daha ayrıntılı araştırmak ve klinik uygulamada potansiyel kullanımını doğrulamak için daha ileri çalışmaların tasarlanması gerekmektedir.

\section{KAYNAKLAR}

1. Zhao W, Zhou S, Yao W, Gan X, Su G, Yuan D, Hei Z. Propofol prevents lung injury after intestinal ischemia-reperfusion by inhibiting the interaction between mast cell activation and oxidative stress. Life Sci. 2014;108(2):80-87.

2. Harward TR, Brooks DL, Flynn TC, Seeger JM. Multiple organ dysfunction after mesenteric artery revascularization. J Vasc Surg. 1993;18(3):459-467.

3. Kim K, Li Y,Jin G, Chong W, Liu B, Lu J, Lee K, Demoya M, Velmahos GC, Alam HB. Effect of valproic acid on acute lung injury in a rodent model of intestinal ischemia reperfusion. Resuscitation 2012; 83: 243-248.

4. Huang X, Zhao W, Hu D, Han X, Wang H, Yang J, Xu Y, Li Y, Yao W, Chen C. Resveratrol efficiently improves pulmonary function via stabilizing mast cells in a rat intestinal injury model. Life Sci. 2017; 15:185:30-37.

5. Zhang F, Li ZL, Xu XM, Hu Y, Yao JH, Xu W, Jing HR, Wang S, Ning SL, Tian XF. Protective effects of icariin-mediated SIRT1/ FOXO3 signaling pathway on intestinal ischemia/reperfusioninduced acute lung injury. Mol Med Rep. 2015; 11(1):269-276.

6. Turan I, Sayan Ozacmak H, Ozacmak VH, Barut F, Ozacmak ID. The effects of S-nitrosoglutathione on intestinal ischemia reperfusion injury and acute lung injury in rats: Roles of oxidative stress and NF-kB. Tissue Cell 2018; 52:35-41. 
7. Bayomy NA, Elshafhey SH, ElBakary RH, Abdelaziz EZ. Protective effect of hesperidin against lung injury induced by intestinal ischemia/reperfusion in adult albino rats: Histological, immunohistochemical and biochemical study. Tissue Cell 2014; 46:304-310.

8. Zu G, Guo J, Che N, Zhou T, Zhang X. Protective effects of ginsenoside $\operatorname{Rg} 1$ on intestinal ischemia/reperfusion injuryinduced oxidative stress and apoptosis via activation of the Wnt/ $\beta$-catenin pathway. Sci Rep. 2016; 6: 38480-34490.

9. Vasileiou I, Kalimeris K, Nomikos T, Xanthopoulou MN, Perrea D, Agrogiannis G, Nakos G, Kostopanagiotou G. Propofol prevents lung injury following intestinal ischemiareperfusion. J Surg Res. 2012; 172(1):146-152.

10. Karimipour M, Shojaei Zarghani S, Mohajer Milani M, Soraya H. Pre-Treatment with Metformin in Comparison with PostTreatment Reduces Cerebral Ischemia Reperfusion Induced Injuries in Rats. Bull Emerg Trauma. 2018; 6(2):115-121.

11. Ge XH, Zhu GJ, Geng DQ, Zhang HZ, He JM, Guo AZ, Ma $\mathrm{LL}, \mathrm{Yu} \mathrm{DH}$. Metformin protects the brain against ischemia/ reperfusion injury through PI3K/Akt1/JNK3 signaling pathways in rats. Physiol Behav. 2017; 170:115-123.

12. El Messaoudi S, Rongen GA, de Boer RA, Riksen NP. The cardioprotective effects of metformin. Curr Opin Lipidol. 2011; 22(6):445-453.

13. Liu Y, Tang G, Zhang Z, Wang Y, Yang GY. Metformin promotes focal angiogenesis and neurogenesis in mice following middle cerebral artery occlusion. Neurosci Lett. 2014; 579:46-51.

14. El-Mir M-Y, Detaille D, Gloria R, Delgado-Esteban M, Guigas B, Attia S, et al. Neuroprotective role of antidiabetic drug metformin against apoptotic cell death in primary cortical neurons. J Mol Neurosci. 2008; 34(1):77-87.

15. Ashabi G, Khodagholi F, Khalaj L, Goudarzvand M, Nasiri M. Activation of AMP-activated protein kinase by metformin protects against global cerebral ischemia in male rats: Interference of AMPK/PGC-1 $\alpha$ pathway. Metab Brain Dis. 2014; 29(1):47-58.

16. Abd-Elsameea A, Moustaf A, Mohamed A. Modulation of the oxidative stress by metformin in the cerebrum of rats exposed to global cerebral ischemia and ischemia/reperfusion. Eur Rev Med Pharmacol Sci. 2014;18(16):2387-2392.

17. Pirat A, Zeyneloglu P, Aldemir D, Yücel M, Ozen O, Candan $S$, Arslan G. Pretreatment with simvastatin reduces lung injury related to intestinal ischemia-reperfusion in rats. Anesth Analg 2006;102(1):225-232.
18. Casini A, Ferrali M, Pampella A, Maellaro E, Comporti M. Lipid peroxidation and cellular damage in extrahepatic tissues of bromobenzene-intoxicated mice. Am J Pathol. 1986;123:520-531.

19. Aykac G, Uysal M, Yalan AS, Kocak-Toker N, Sivas A, $\mathrm{Oz} \mathrm{H}$. The effects of chronic ethanol injection on hepatic lipid peroxide, glutathione, glutathione peroxidase and glutathione transferase in rats. Toxicol. 36:71-76.

20. Mo LQ, Chen Y, Song L, Wu GM, Tang N, Zhang YY, Wang $\mathrm{XB}$, Liu KX, Zhou J. Osthole prevents intestinal ischemiareperfusion-induced lung injury in a rodent model. J Surg Res. 2014; 189(2):285-294.

21. Barut F, Ozacmak VH, Turan I, Sayan-Ozacmak H, Aktunc E. Reduction of Acute Lung Injury by Administration of Spironolactone After Intestinal Ischemia and Reperfusion in Rats. Clin Invest Med. 2016; 39(1):E15-24.

22. Ghadernezhad N, Khalaj L, Pazoki-Toroudi H, Mirmasoumi M, Ashabi G. Metformin pretreatment enhanced learning and memory in cerebral forebrain ischaemia: The role of the AMPK/BDNF/P70SK signalling pathway. Pharm Biol. 2016; 54(10):2211-2219.

23. Cahova M, Palenickova E, Dankova H, Sticova E, Burian M, Drahota Z, Cervinkova Z, Kucera O, Gladkova C, Stopka P, Krizova J, Papackova Z, Oliyarnyk O. Metformin prevents ischemia reperfusion-induced oxidative stress in the fatty liver by attenuation of reactive oxygen species formation. Am J Physiol Gastrointest Liver Physiol. 2015; 309(2):G100-111.

24. Tang G, Yang H, Chen J, Shi M, Ge L, Ge X, Zhu G. Metformin ameliorates sepsis-induced brain injury by inhibiting apoptosis, oxidative stress and neuroinflammation via the PI3K/Akt signaling pathway. Oncotarget 2017; 8(58):97977-97989.

25. Marzi I, Bühren V, Schüttler A, Trentz O. Value of superoxide dismutase for prevention of multiple organ failure after multiple trauma J Trauma 1993; 35: 110-119.

26. Kalimeris K, Briassoulis P, Ntzouvani A, Nomikos T, Papaparaskeva K, Politi A, Batistaki C, Kostopanagiotou G. $\mathrm{N}$-acetylcysteine ameliorates liver injury in a rat model of intestinal ischemia reperfusion. J Surg Res. 2016; 206(2):263272.

27. Yang B, Ni YF, Wang WC, Du HY, Zhang H, Zhang L, Zhang WD, Jiang T. Melatonin attenuates intestinal ischemia-reperfusion-induced lung injury in rats by upregulating N-myc downstream-regulated gene 2. J Surg Res. 2015; 194(1):273280. 